\title{
Students' perception of the learning environment in private-sector pharmacy institutes of Pakistan
}

\author{
Samra Bashir ${ }^{1}$ (D) , Arif-ullah Khan², Maryam Mahmood ${ }^{2}$, Mateen Abbas ${ }^{1}$, Samar Akhtar ${ }^{3}$, Abdul Waheed Khan ${ }^{4}$, \\ Muhammad Tahir Aqeel ${ }^{5}$, Muhammad Akhlaq ${ }^{6}$ \& Hamaad Ahmad 3 \\ ${ }^{1}$ Capital University of Science and Technology, Islamabad, Pakistan \\ ${ }^{2}$ Riphah Institute of Pharmaceutical Sciences, Riphah International University, Islamabad, Pakistan \\ ${ }^{3}$ Yusra Institute of Pharmaceutical Sciences, Islamabad, Pakistan \\ ${ }^{4}$ Department of Pharmacy, University of Lahore, Islamabad, Pakistan \\ ${ }^{5}$ Margalla College of Pharmacy, Margalla Institute of Health Sciences, Rawalpindi, Pakistan \\ ${ }^{6}$ Department of Pharmacy, Abasyn Univeristy Islamabad Campus, Islamabad, Pakistan
}

\section{Keywords \\ Pharmacy Institutes \\ Student's Perception \\ Learning Environment \\ DREEM}

Correspondence
Dr Samra Bashir
Department of Pharmacy
Capital University of Science \&
Technology
Islamabad Expressway
Kahuta Road
Zone-V Islamabad
Pakistan
samrabashir@gmail.com

\begin{abstract}
Introduction: A conducive learning environment is crucial to the effective delivery of curriculum and professional and social development of the students. This cross-sectional study was conducted to investigate students' perception of the learning environment in private-sector pharmacy institutes of Pakistan. Methods: The overall learning environment and its various aspects were compared between different pharmacy institutes, year of study and gender. Questionnaires, based on the Dundee Ready Education Environment Measure (DREEM) and demographic information, were completed by 527 undergraduate pharmacy students enrolled at six private-sector pharmacy institutes in Pakistan. Participants were selected by convenience sampling and the scores were compared across grouping variables identified via demographic information. Results: The total DREEM score across the sample was $116.10 \pm 25.39$ (mean \pm S.D), indicating an overall positive perception of the learning environment among students of the private-sector pharmacy institutes. Similarly, the subscale scores also reflected students' positive perception of various aspects of the educational environment including learning, teachers, institutional atmosphere, academic self-perception and social self-perception across the sample. Total DREEM score and sub-scale scores were consistent between male and female students and across all years of Pharm. D. programme included in this study. Scores of the individual institutes reflect the prevalence of an overall conducive learning environment in the private-sector pharmacy institutes under study. A comparison of the total DREEM score and sub-scale scores of the individual institutes also reflects that learning environment of a few institutes, as perceived by their respective students, is significantly better than the others. Conclusion: The positive perception held by the students of private-sector pharmacy institutes in Pakistan is suggestive of the existence of a conducive learning environment that is contributory towards students' learning of professional and social abilities.
\end{abstract}

\section{Introduction}

Pharmacy education was started in Pakistan in 1948 as an undergraduate degree programme by the University of the Punjab, a public-sector university (Khan, 2011). Pharmacy education had been offered solely by publicsector universities till the late 1990s, when, recognising the emerging need of pharmacy graduates in Pakistan, the private-sector institutes were also authorised to offer the Doctor of Pharmacy (Pharm.D.) programme. Pharm.D. is a five-year professional degree programme in Pharmacy, requiring twelve years of schooling as a Higher Secondary School Certificate, in premedical subjects such as 
chemistry, physics and biology, or A-levels in similar subjects, as a prerequisite for admission to the programme. Although the Pharmacy Council of Pakistan (PCP) has recommended to implement internship in various areas of the pharmacy profession, it is still not a mandatory requirement for securing a job in the public- or private-sector.

Today more than sixty institutes including private-sector universities, affiliated private colleges and public-sector universities are offering Pharm.D. programme (PCP, 2019a). Of these institutes, private-sector pharmacy institutes not only outnumber the public-sector universities but their graduates are also serving in diverse areas of the pharmacy profession on par with the public-sector university graduates. All pharmacy institutes of Pakistan have adopted a unified Pharm.D. curriculum, developed by the Higher Education Commission of Pakistan, which is also a requisite for accreditation with $\mathrm{PCP}$ and a requirement by PCP for a pharmacist to get a license for practice in Pakistan (Khan, 2011). The Pharm.D. curriculum is designed to provide education in diverse areas of the pharmacy profession including pharmaceutical manufacturing and quality control, retail, community, hospital and clinical pharmacies and regulation of drug manufacturing, sale and purchase (PCP, 2019b). The curriculum is therefore quite extensive and education in pharmacy institutes is quite stressful for students. Content is delivered mainly through traditional modes of learning including lectures, tutorials, and labs alongside field visits and clinical clerkship over the last two years only.

The learning environment of an institute comprises of all related factors that may affect the learning of the students including curriculum structure, teaching methodology, teaching/learning resources, organisational culture, and the style of institutional leadership (Ezeala \& Moleki, 2018). Existence of a challenging and competitive environment in each area of the pharmacy profession requires knowledgeable, skilful and professionally groomed individuals to fulfil the expanding role of pharmacists. A conducive learning environment at pharmacy institutes is key to the effective delivery of pharmacy curriculum as well as the professional development of the students (Ezeala \& Moleki, 2018). As the learning environment is both measurable and changeable, it is important to assess the educational environment of an institution regularly so as to identify the areas needing attention and to foster the areas of excellence, to ensure that students are provided with a conducive learning environment needed to advance students' performance and institutional development. Students' perception of their educational environment is the primary mean to establish the effectiveness of the learning environment (Miles et al., 2012).

As private-sector institutes are significantly contributing to pharmacy education in Pakistan, and the emerging institutes are mainly from this sector, there is a need to assess how well the requirement for the standard learning environment is met in these institutes. The aim of this study was therefore to assess students' perceptions of learning environments in private-sector pharmacy institutes of Islamabad and Rawalpindi, the geographically contiguous cities of Pakistan, and identify respective strengths and areas in need of further improvement in these institutes.

\section{Methods}

In this study, the authors assessed the educational environment prevailing at private-sector pharmacy institutes of Islamabad and Rawalpindi, using a prevalidated and widely used tool Dundee Ready Educational Environment Measure (DREEM). DREEM was introduced in the late 1990s by a panel of 30 health professional educators and then validated through testing on students in several countries (Roff et al., 1997; Miles et al., 2012). The tool was originally designed for the assessment of the educational environment in medical and other health professions institutes but has also been employed and validated with little modifications for institutes offering pharmacy and other allied health professions and nonmedical education (Brown et al., 2011; Atapattu et al., 2015; Ezeala \& Moleki, 2017; Ezeala \& Moleki, 2018; Memon et al., 2018). The DREEM questionnaire constituting of 50 items, to be answered on a five-point Likert scale. Each of these items were scored 0-4 (from strongly disagree [SD] to strongly agree [SA]) except for nine items $(4,8,9,17,25,35,39,48$ and 50$)$ which were reversed scored $0-4$ (from SA to SD). The DREEM questionnaire reflects the student's perception of five main aspects of the educational environment including: Student's perceptions of learning (SPL); Student's perceptions of teachers (SPT); Student's academic selfperceptions (SASP); Student's perceptions of atmosphere (SPA); and Student's social self-perceptions (SSSP) as subscales. Each of these domains is assessed through a specified set of items having a specified total score to determine the strength of an academic institute in the given area: SPL by 12 items with the maximum score of 48 ; SPT by 8 items with the maximum score 32; SASP by 11 items with the maximum score of 44; SPA by 12 items with the maximum score 48; whereas, SSSP is assessed by 
7 items with the maximum score of 28 . Where the maximum score in each subarea of the educational environment: SPL, SPT, SASP, APA and SSSP, reflects an ideal situation, the scores of $>24,>22,>16,>24$ and $>14$ represent a positive trend in the respective areas. Similarly, the maximum DREEM score of 200 , as calculated by adding scores of all the 50 items, represents an overall ideal educational environment. However, for the other values, a total DREEM score of $<50$ is interpreted as 'Very Poor', 50-100 as 'Plenty of Problems', 100-150 as 'More Positive than Negative' and 150-200 as 'Excellent', according to the previous studies (McAleer \& Roff, 2001; Miles et al., 2012).

This cross-sectional survey was conducted in Islamabad and Rawalpindi from November 2018 to April 2019 to evaluate teaching environment at private-sector pharmacy institutes of the twin cities of Pakistan. The study participants were drawn from the undergraduate students of Pharm.D. programme from all private-sector pharmacy institutes of the two cities who volunteered to participate in this study. As the students were to reflect on their previous year(s) experience, students of 2 nd year to 5 th year were included in the study. First-year students were not included in the study as they had just joined the course and were not yet in a position to comment on the educational environment. Students of both genders and all ethnic groups were included. Variables like parent/ guardian occupation and income were also recorded. There were no exclusion criteria applicable among students of 2 nd to 5 th year. Sample size for the study was calculated using a margin of error of $5 \%$, a confidence level of $95 \%$ with a response distribution of $50 \%$. There are a total of seven private-sector pharmacy institutes in Islamabad and Rawalpindi with undergraduate pharmacy student strength of around 2000. As the educational environment of these institutes was aimed to ascertain collectively, the sample size was calculated considering 2000 students as the total population of undergraduate pharmacy students in all the private-sector institutes of Islamabad and Rawalpindi and this gave a sample size of minimum 324 students. As six institutes agreed to participate in this study, a sample of not less than 54 students was drawn from each of these institutes.

After obtaining approval from the respective ethics committee or the respective authority of each institute, the data was collected by three researchers. To avoid any bias and influence on the student's response, it was ascertained that data from a given institute is collected by a researcher not belonging to that institute. Six hundred DREEM questionnaire was distributed to second to the fifth-year pharmacy students at each institution during the month of November 2018. Before the students completed the questionnaire, they were informed about the purpose of collecting the data as well as the data collection procedure, including anonymity and voluntary participation. The participants' consent to take part in the study was inferred by their completion of the questionnaire. Students were given approximately 30 minutes to complete the questionnaire and were left unsupervised during this time. The basic information of the students was also recorded, however, anonymity was maintained. While entering data into computers for statistical analysis, institutes were coded as Institute 1 to 6 to evaluate any difference between the institutes without disclosing their identity.

The data were entered in Microsoft Excel spreadsheets and statistical analysis was carried out using SPSS v.20.0 for Windows. The overall mean DREEM scores and the sub-scales scores are reported as mean \pm standard deviation (S.D.), whereas the categorical variables are presented as frequency and percentages. Non-parametric analyses was performed to proceed for comparative and association analyses. The mean DREEM scores and subareas scores were compared between genders using the Mann-Whitney $U$ test. For comparing mean scores among students of second to fifth year and the six institutes, Kruskal Wallis test was run. Tukey's test was further used to observe a pair-wise comparison of scores. $\mathrm{P}<0.05$ was considered significant.

\section{Results}

Out of 600 questionnaires distributed among undergraduate pharmacy students of Year 2 to 5, belonging to six pharmacy institutes, 527 questionnaires were filled in completely and returned to the researchers. Of the 527 students who responded, 145 (27.5\%) were males and 382 (72.5\%) were females. 182 (34.53\%) students were in the age bracket 17-21 years, 240 (45.54\%) in 21-23 years, 90 (17.07\%) in 23-25 years and 15 (2.84\%) students were in the age range of $25-27$ years. There were 139 (26.4\%) students from the 2nd year, 120 (22.8\%) students from the 3rd year, 107 (20.3\%) students from the 4th year and $161(30.6 \%)$ students from the 5th year. As data were collected from six institutes of Islamabad and Rawalpindi, participants from each of the institute, numbered from I-VI, were 163, 83, 55, 70, 60 and 96, respectively (Table I).

The collective overall DREEM score of all the pharmacy institutes was $116.10 \pm 25.39$ (range 109.08 \pm 20.97 to $129.41+21.41)$. None of the institutes scored less than 
100. The collective rating of pharmacy institutes for the DREEM sub-scale was $28.79 \pm 6.75$ for SPL, $24.59 \pm 6.20$ for SPT, $18.51 \pm 4.91$ for SASP, $27.92 \pm 8.48$ for SPA and $16.28 \pm 4.02$ for SSSP (Table II).

Table I: Demographics of the study population $(N=527)$

\begin{tabular}{lcc}
\hline Characteristics & Frequency ( $\mathbf{n})$ & Percentage (\%) \\
\hline Gender & & \\
Male & 145 & 27.5 \\
Female & 382 & 72.5 \\
\hline Age & & \\
$17-21$ & 182 & 34.53 \\
$21-23$ & 240 & 45.54 \\
$23-25$ & 90 & 17.07 \\
$25-30$ & 15 & 2.84 \\
\hline Number of students from each professional year & \\
$2^{\text {nd }}$ year & 139 & 26.4 \\
$3^{\text {rd }}$ year & 120 & 22.8 \\
$4^{\text {th }}$ year & 107 & 20.3 \\
$5^{\text {th }}$ year & 161 & 30.6 \\
\hline Number of students from each pharmacy institute & \\
Institute I & 163 & 30.9 \\
Institute II & 83 & 15.7 \\
Institute III & 55 & 10.4 \\
Institute IV & 70 & 13.3 \\
Institute V & 60 & 11.4 \\
Institute VI & 96 & 18.2 \\
\hline
\end{tabular}

Table II: Total DREEM score and sub-scale scores of the private sector pharmacy institutes

\begin{tabular}{lcc}
\hline DREEM Scales & Score & Rating \\
\hline $\begin{array}{l}\text { Student's perception } \\
\text { of learning }\end{array}$ & $28.79 \pm 6.75$ & $\begin{array}{c}\text { A more positive } \\
\text { perception }\end{array}$ \\
\hline $\begin{array}{l}\text { Student's perception } \\
\text { of teachers }\end{array}$ & $24.59 \pm 6.20$ & $\begin{array}{c}\text { Moving in the right } \\
\text { direction }\end{array}$ \\
\hline $\begin{array}{l}\text { Student's academic } \\
\text { self-perception }\end{array}$ & $18.51 \pm 4.91$ & $\begin{array}{c}\text { Feeling more on the } \\
\text { positive side }\end{array}$ \\
\hline $\begin{array}{l}\text { Student's perception } \\
\text { of atmosphere }\end{array}$ & $27.92 \pm 8.48$ & \begin{tabular}{c} 
A more positive attitude \\
\hline $\begin{array}{l}\text { Student's social self- } \\
\text { perception }\end{array}$
\end{tabular} \\
$\begin{array}{lcc}\text { Total DREEM score } & 16.28 \pm 4.02 & \text { Not too bad } \\
& 16.10 \pm 25.39 & \text { More positive than } \\
\text { negative }\end{array}$ \\
$\begin{array}{l}\text { Values are given as mean } \pm \text { S.D } \\
\text { DREEM: Dundee Ready Educational Environment Measure }\end{array}$
\end{tabular}

There was no difference in the mean total DREEM score as well as scores of the sub-scales between the female and the male students (Table III).
Table III: Comparison of DREEM scores with respect to gender

\begin{tabular}{lccc}
\hline DREEM Scales & Male & Female & $p$-value \\
\hline $\begin{array}{l}\text { Student's } \\
\text { perception of } \\
\text { learning }\end{array}$ & $28.63 \pm 6.59$ & $28.85 \pm 6.81$ & 0.715 \\
\hline $\begin{array}{l}\text { Student's } \\
\text { perception of } \\
\text { teachers }\end{array}$ & $24.08 \pm 6.19$ & $24.79 \pm 6.20$ & 0.199 \\
\hline $\begin{array}{l}\text { Student's } \\
\text { academic self- } \\
\text { perception }\end{array}$ & $18.77 \pm 5.22$ & $18.41 \pm 4.79$ & 0.546 \\
\hline $\begin{array}{l}\text { Student's } \\
\text { perception of } \\
\text { atmosphere }\end{array}$ & $27.34 \pm 9.11$ & $28.14 \pm 8.23$ & 0.424 \\
\hline $\begin{array}{l}\text { Student's social } \\
\text { self-perception }\end{array}$ & $16.07 \pm 3.74$ & $16.37 \pm 4.12$ & 0.301 \\
\hline $\begin{array}{l}\text { Total DREEM } \\
\text { score }\end{array}$ & $114.88 \pm 25.27$ & $116.56 \pm 25.46$ & 0.440 \\
\hline
\end{tabular}

Values given are mean \pm S.D.

DREEM: Dundee Ready Educational Environment Measure

For statistical comparisons Mann-Whitney $U$ test was performed.

Between the students of the 2nd to 5th year, the overall mean DREEM score was $116.73 \pm 25.37$ among 2 nd year students, $117.68 \pm 25.15$ among 3rd year, 118.96 \pm 22.37 among 4th year, and $112.47 \pm 27.21$ among 5th year students. There was no difference among students of different professional years in overall DREEM score as well as sub-scales scores (Table IV).

The difference in overall DREEM score was significant $(p<0.001)$ between the six institutes that participated in this study. Pair-wise analysis of difference among the pharmacy institutes of Islamabad reflected that the total mean DREEM score of two institutes (II and VI) was significantly higher than at least one other institute (Table V). Institute IV scored higher than Institute I $(p<0.001)$, III $(p<0.01)$ and $V(p<0.001)$. Institute II scored higher than institute $V$ only $(p<0.05)$. There was also a significant difference $(p<0.0001)$ between the institutes for the subscales scores. Only the students of Institute IV rated their institute significantly better than at least two other institutes in all the five sub-scales. In sub-scale SPL, the rating of institute IV was significantly higher $(p<0.0001)$ than Institutes, I, II, III and V, whereas Institute II $(p<0.05)$ and $\mathrm{VI}(p<0.05)$ rated higher than Institute V. SPT was better in Institute IV than the two other Institutes: I $(p<0.001)$ and III $(p=0.01)$. For SASP, only Institute IV scored significantly higher than two other Institutes including Institute I $(p<0.01)$ and Institute V $(p=0.001)$. Rating for the measure SPA was significantly higher for two Institutes: Institute II scored higher than I ( $p<0.01)$, III $(p<0.01)$ and $V(p<0.01)$, whereas, Institute IV was also 
Table IV: Comparison of DREEM Scores with respect to the professional year

\begin{tabular}{|c|c|c|c|c|c|}
\hline DREEM Scales & $2^{\text {nd }}$ Prof. & $3^{\text {rd }}$ Prof. & $4^{\text {th }}$ Prof. & $5^{\text {th }}$ Prof. & $p$-value \\
\hline $\begin{array}{l}\text { Student's perception of } \\
\text { learning }\end{array}$ & $29.17 \pm 6.76$ & $29.63 \pm 6.52$ & $28.90 \pm 6.09$ & $27.77 \pm 7.24$ & 0.210 \\
\hline $\begin{array}{l}\text { Student's perception of } \\
\text { teachers }\end{array}$ & $24.94 \pm 6.47$ & $25.36 \pm 5.96$ & $24.54 \pm 5.59$ & $23.75 \pm 6.47$ & 0.089 \\
\hline $\begin{array}{l}\text { Student's academic self- } \\
\text { perception }\end{array}$ & $18.67 \pm 5.00$ & $18.44 \pm 4.37$ & $19.27 \pm 4.74$ & $17.91 \pm 5.27$ & 0.286 \\
\hline $\begin{array}{l}\text { Student's perception of } \\
\text { atmosphere }\end{array}$ & $27.79 \pm 8.95$ & $28.01 \pm 8.58$ & $29.29 \pm 7.35$ & $27.06 \pm 8.66$ & 0.131 \\
\hline $\begin{array}{l}\text { Student's social self- } \\
\text { perception }\end{array}$ & $16.16 \pm 3.53$ & $16.24 \pm 3.81$ & $16.96 \pm 3.82$ & $15.98 \pm 4.63$ & 0.497 \\
\hline Total DREEM score & $116.73 \pm 25.39$ & $117.68 \pm 25.15$ & $118.96 \pm 22.37$ & $112.47 \pm 27.21$ & 0.097 \\
\hline
\end{tabular}

Values given are mean \pm S.D.

DREEM: Dundee Ready Educational Environment Measure

For statistical comparisons Kruskal-Wallis test was run followed by Tukey's test for pair-wise comparison of the scores

Table V: Comparison of DREEM scores between the individual Pharmacy institutes

\begin{tabular}{|c|c|c|c|c|c|c|c|}
\hline DREEM Scales & Institute I & Institute II & Institute III & Institute IV & Institute V & Institute VI & $p$-value \\
\hline $\begin{array}{l}\text { Student's perception } \\
\text { of learning }\end{array}$ & $28.50 \pm 5.83$ & $28.63 \pm 8.20$ & $27.20 \pm 6.52$ & $32.31 \pm 6.33$ & $26.30 \pm 6.03$ & $29.32 \pm 6.73$ & $<0.0001$ \\
\hline $\begin{array}{l}\text { Student's perception } \\
\text { of teachers }\end{array}$ & $23.43 \pm 4.80$ & $24.59 \pm 7.56$ & $23.71 \pm 5.65$ & $27.39 \pm 5.94$ & $25.27 \pm 6.39$ & $24.61 \pm 6.80$ & $<0.0001$ \\
\hline $\begin{array}{l}\text { Student's academic } \\
\text { self-perception }\end{array}$ & $18.09 \pm 4.64$ & $18.31 \pm 5.86$ & $18.98 \pm 5.91$ & $20.31 \pm 4.06$ & $17.25 \pm 3.76$ & $18.58 \pm 4.74$ & 0.001 \\
\hline $\begin{array}{l}\text { Student's perception } \\
\text { of atmosphere }\end{array}$ & $26.77 \pm 7.44$ & $30.06 \pm 9.13$ & $25.29 \pm 8.94$ & $31.81 \pm 7.04$ & $24.82 \pm 8.84$ & $28.65 \pm 8.60$ & $<0.0001$ \\
\hline $\begin{array}{l}\text { Student's social self- } \\
\text { perception }\end{array}$ & $15.50 \pm 3.24$ & $16.76 \pm 4.83$ & $17.53 \pm 5.41$ & $17.59 \pm 3.34$ & $15.45 \pm 3.06$ & $16.07 \pm 4.11$ & $<0.0001$ \\
\hline Total DREEM score & $112.28 \pm 21.43$ & $118.35 \pm 32.33$ & $112.71 \pm 26.63$ & $129.41 \pm 21.41$ & $109.08 \pm 20.97$ & $117.24 \pm 26.00$ & $<0.0001$ \\
\hline
\end{tabular}

rated higher than institutes I ( $p<0.001)$, III $(p<0.001)$ and V $(p<0.001)$. Similarly, SSSP was significantly better for Institute IV than Institute I $(p<0.001)$ and Institute $V$ $(p<0.01)$.

\section{Discussion}

Pharmacy education in Pakistan is focused to produce graduates with requisite competencies to serve in diverse areas of pharmacy profession including the production of pharmaceuticals, hospital pharmacy, community pharmacy, clinical pharmacy, sales and marketing of pharmaceuticals, drug regulatory affairs, and teaching and research (Azhar et al., 2009). As the Pharm.D. curriculum adopted by all pharmacy institutes in Pakistan is predefined, developing an effective educational environment that would inculcate essential capabilities and skills to produce competent pharmacists who could fulfil professional needs of society is mandatory. Hence evaluation of the educational environment in academic institutes should be part of effective educational practice. The DREEM scale, a measure of institutional learning environment based on the student's perspective, has effectively been employed as a tool for this purpose (Ezeala \& Moleki, 2018; Memon et al., 2018). As the private-sector is a relatively new partaker in pharmacy education and is exceeding in number over public-sector institutes, this study was conducted to ascertain how the educational environment prevailing in private-sector pharmacy institutes of Pakistan is perceived by the students.

The collective mean total DREEM score of all the pharmacy institutes participated in this study was $116.10+25.39$. As none of the institutes scored less than 
100, it indicates that a more positive educational environment is generally perceived in these institutes (Roff et al., 1997; Miles et al., 2012;). Similarly, scores of sub-scales for each of these institutes also fall within range reflecting a positive trend in the specific areas as well (Miles et al., 2012; Ezeala \& Moleki, 2018).

A review of the literature reflects that only a few pharmacy institutes have previously been evaluated for their educational environment through the DREEM scale. There is only one report from Pakistan on the educational environment of a public-sector university providing pharmacy education and a few reports from other countries (Brown et al., 2011; Ezeala \& Moleki, 2017; Ezeala \& Moleki, 2018), whereas, the educational environment of the private-sector academic institutes in Pakistan has not been evaluated before. The students' rating of the private pharmacy institutes for the total DREEM score, as determined in this study, was found to be similar to a previous report from a public-sector university of Pakistan, thereby, suggesting that the students of private-sector pharmacy institutes/universities of Islamabad and Rawalpindi are equally satisfied with their educational environment. Among the sub-scale scores, the social self-perception of the private-sector pharmacy students was rated higher than the publicsector university reported previously. This suggests that an overall positive educational environment prevails in private-sector pharmacy institutes of Islamabad and Rawalpindi.

In this current study, the majority of the students taking the survey were females. The overall DREEM score and sub-scales scores of the female students were comparable to that of the male students. The gender-wise difference in perception of the educational environment in pharmacy institutes has previously been evaluated by one study conducted at Monash University, Australia (Brown et al., 2011). The study revealed a better perception of the educational environment by female students than male students. Similarly, several studies on institutes imparting medical education have revealed better self-perception of educational environment by female undergraduate medical students than the male students (Brown et al., 2011; Rehman et al., 2017). However, in this study, the authors could not see any gender-wise disparity in perception of the learning environment in the pharmacy institutes of Pakistan. Similarly, the year-wise difference in students' perception among four professional years as well as between clinical (Year 1 to 3 ) and preclinical (Year 4 and 5) years didn't exist. This finding is consistent with a previous study from Pakistan which has reported no difference between clinical and preclinical year students' perception of their learning environment (Memon et al., 2018). This could be because most of the teaching and training of the students even during the clinical years is carried out at their parent institutes and student visits to the hospitals are for a limited time only. Data from individual private-sector pharmacy institutes of Islamabad and Rawalpindi revealed the existence of a conducive learning environment in all the institutes which participated in this survey. A couple of these institutes were rated significantly better than other institutes by their students. Respective total and sub-scales scores and the ranking of each of the six participating institutes from this study, based on DREEM assessment, have been communicated to all the institutes individually, so that they may apprise of their educational environment, related strengths and the areas to be focused on for further improvement.

\section{Conclusion}

This DREEM based evaluation of private-sector pharmacy institutes of Islamabad and Rawalpindi validates the existence of a conducive academic environment with reference to learning, teaching, atmosphere, sense of well-being, academic self-perception and achievement in all private-sector pharmacy institutes of Islamabad and Rawalpindi. Both male and female genders and students of all academic years who participated in the study are consistently satisfied with their institution's educational environment. However, these findings are based on the perception of undergraduate pharmacy students who have very limited practical exposure of the pharmacy profession, therefore, a similar study should be conducted to get feedback from interns and serving graduates of pharmacy. Such a study will help to verify the effectiveness of the institutional learning environment in producing pharmacy graduates who perceive themselves adequately equipped with the requisite knowledge and skills to fulfil their professional responsibilities and pursue their career smoothly and successfully.

\section{References}

Atapattu, N.S.B.M., Kumari, K.K.E.I.U., Pushpakumara, K.K.A., \& Mudalige, S.K.K. (2015). Adoption of Dundee DREEM Questionnaire to assess the educational environment of an agriculture degree programme. Tropical Agricultural Research \& Extension, 18(1), 22-30. https://doi.org/10.4038/ tare.v18i1.5321 
Azhar, S., Hassali, M.Z., Ibrahim, M.I.M., Ahmad, M., Masood, I., \& Shafie, A.A. (2009). The role of pharmacists in developing countries: the current scenario in Pakistan. Human Resources for Health, 7(54). https://doi.org/10.1186/1478-4491-7-54

Brown, T., Williams, B., \& Lynch, M. (2011) The Australian DREEM: evaluating student perceptions of academic learning environments within eight health science courses. International Journal of Medical Education, 2, 94-101. https://doi.org/ 10.5116/iime.4e66.1b37

Ezeala, C.C., \& Moleki, M.M. (2017). Analysis of Undergraduate Students' Perception of the Educational Environment of a Medical School in Zambia Provided a Framework for Strategic Planning. British Journal of Medicine and Medical Research, 21(5), 1-9. https://doi.org/10.9734/BJMMR/2017/33545

Ezeala, C.C., \& Moleki, M.M. (2018). Evaluation of the educational environments of undergraduate medicine and pharmacy programmes at the University of Zambia. Research and Development in Medical Education, 7(1), 14-20. https:// doi.org/10.15171/rdme.2018.004

Khan, T.M. (2011). Challenges to pharmacy and pharmacy practice in Pakistan. Australasian Medical Journal, 4(4), 230-235. https://doi.org/10.4066/AMJ.2011.488

McAleer, S., \& Roff, S. (2001). A practical guide to using the Dundee Ready Education Environment Measure (DREEM). In J.M. Genn (Ed.), Curriculum, Environment, Climate, Quality and Change in Medical Education: A Unifying Perspective (pp.29-33). Scotland: The Association for Medical Education in Europe (AMEE)

Memon, A.R., Ali, B., Kiyani, M.M., Ahmed, I., Memon, A., \& Feroz, J. (2018). Physiotherapy and pharmacy students' perception of educational environment in a medical university from Pakistan. Journal of Pakistan Medical Association, 68, 71-75.

Miles, S., Swift, L., \& Leinster, S.J. (2012). The Dundee Ready Education Environment Measure (DREEM): A review of its adoption and use. Medical Teacher, 34, e620-e634. https:// doi.org/10.3109/0142159X.2012.668625

PCP [Pharmacy Council of Pakistan]. (2019a). Institutions (online). Available at: https://www.pharmacycouncil.org.pk/PI.php

PCP [Pharmacy Council of Pakistan]. (2019b). Revised Pharm.D., curriculum 2013. (online). Available at: https://www.pharmacy council.org.pk/doc/Pharm\%20D\%20Curriculum\%20Final\%2020 13.pdf

Rehman, R., Ghias, K., Fatima, S.S., Hussain, M., \& Alam, F. (2017). Dream of a conducive learning environment: One DREEM for all medical students!. Journal of Pakistan Medical Association, 67, 7-11

Roff, S., McAleer, S., Harden, R.M., Al-Qahtani, M., Ahmed, A.U., Deza, H., Groenen, G., \& Primparyon, P. (1997). Development and validation of the Dundee Ready Education Environment Measure (DREEM). Medical Teacher, 19(4), 295-299. https:// doi.org/10.3109/01421599709034208 